\title{
Research on Mechanism of Rock Burst in Key Working Faces under Thick Magmatite in Deep Mine
}

\author{
WeiLi Yang $\mathbb{D}^{1}{ }^{1}$ ZhiZeng Zhang $\mathbb{D}^{1},{ }^{1}$ QuanDe Wei, ${ }^{2}$ XiaoCheng $Q u^{2}$ and JingLin Wen ${ }^{3}$ \\ ${ }^{1}$ Architectural Engineering Department, Zhongyuan University of Technology, Zhengzhou, Henan 451191, China \\ ${ }^{2}$ Beijing Anke Xingye Research Institute Company Limited of Mine Safety Technology, Beijing 102299, China \\ ${ }^{3}$ China Academy of Safety Science and Technology, Beijing 100012, China \\ Correspondence should be addressed to WeiLi Yang; 58633425@qq.com
}

Received 7 January 2021; Revised 14 February 2021; Accepted 18 March 2021; Published 13 April 2021

Academic Editor: Junfei Zhang

Copyright ( $\odot 2021$ WeiLi Yang et al. This is an open access article distributed under the Creative Commons Attribution License, which permits unrestricted use, distribution, and reproduction in any medium, provided the original work is properly cited.

The rock burst of key working faces under the thick hard rock in deep mine significantly threatens the mining safety of deep mine. In this study, the key working faces under typical deeply buried thick magmatite were adopted as the engineering background. The mine pressure characteristics during the mining in key working faces under thick magmatite in deep mine were measured and analyzed. Then, the evolution of overburden strata structure under the control of thick magmatite was explored based on the theory of mine pressure to conclude that the horizontal "carrier" load of broken rock beam, the vertical "loader" load, and the shock bump load from thick magmatite fracture are main sources of force behind the burst. Finally, the mechanism of rock burst was studied on the basis of the balanced relationship between loading and bearing. According to the results of research, the burst in key working faces under thick magmatite in deep mine was actually the instability burst of the key working face block. The bearing capacity and load of key working face block were constantly changing during the unstable movement of thick magmatite. The rock burst would occur in the event of any instability during the dynamic confrontation of "loading-bearing". As per different burst sources, it could be divided into flexural loading burst of thick magmatite and shock bump burst of thick magmatite fracture. The mechanical conditions for each of the two bursts and the width calculation formula for the key working face free from overall instability burst were deduced. The research results were applied to key working face 12310. Meanwhile, the purpose of safe production following the principle of "No disaster in bumps, no harm under burst" was realized by implementing the "Four Keys" comprehensive prevention and control measures of "key monitoring + key speed reduction + key pressure relief + key support".

\section{Introduction}

In recent years, with the gradual depletion of easy-to-mine coal resources in the shallow part and the gradual extension of mining to the deep part, new types of rock burst disasters have emerged continuously while more coal resources have been obtained [1-5], and the rock burst in key working faces is one of them. The main stress source of burst in general working faces is the stress generated by the movement of overburden strata in a certain range above the coal seam [6-9]; however, the overburden from the deep key working face to the earth surface will lose stability after mining, resulting in greater stress and greater damage from the corresponding rock burst. For example, in 2015, the rock burst disaster occurred at key working face 3112 of Shandong Chaoyang Mine, and the entire open-off cut with a range of $120 \mathrm{~m}$ was washed away, causing 8 people injured and hundreds of millions of yuan lost [10]. High-position thick hard strata (with thickness ranging from dozens of meters to hundreds of meters) have the characteristics of high strength and good integrity; however, its unstable movement often brings strong shock bumps and strong rock burst disasters [11-13]. For example, in 2011, a rock burst accident occurred in Yima Qianqiu Coal Mine, which was induced by a strong shock bump (seismic focus energy $\left.3.5 \times 10^{8} \mathrm{~J}\right)$ caused by the movement of thick conglomerate (with thickness about 500m), resulting in 10 deaths, 64 injuries, and direct losses of nearly 100 million yuan [14]. If 
the thick hard rock strata exist in the upper overburden strata above the key working face, dynamic disasters such as rock burst and shock bump would be more serious. As per incomplete statistics, many of the 27 major rock burst accidents in China since 2011 (causing more than 300 casualties and destroying thousands of meters of tunnels) are related to the mining of key working faces under the thick hard rock strata. Through the investigation into many mines in China, it can be found that the key working faces are often formed by mining methods, mining technologies, blind mining, or the discontinuous mining of coal seams on account of avoiding geological structures during mining. There are thick hard rock strata in the overburden strata of many mining areas in our country, such as thick magmatite in Huafeng Mine, thick sandstone in Baodian Mine, and thick conglomerate in Qianqiu Mine, and dynamic disasters in key working faces under the thick hard rock strata occur frequently in these mining areas.

Many scholars have studied the mechanism of rock burst in working faces under thick hard strata. For example, Jiang et al. [15] adopted field actual measurements to reveal the spatial and temporal patterns of micro-shock bump of high-position thick hard strata during repeated mining of the upper and lower coal seams, which effectively prevented and controlled dynamic disasters under thick hard strata. Based on the theory of thin plates, Yang et al. [16] concluded that the thick strata in a sagging zone had the potential for the rock burst to working faces and, in a fracture zone, had the potential for both the rock burst and wide roof weighting to working faces. Jiang et al. [17] studied the mechanism of the rock burst in thick coal seams under the control of thick conglomerate by constructing a spatial structure model of overburden of strata and mining structure and proposed prevention and control measures such as reasonable design of tunnel location and adoption of half coal rock tunnel. Xuan et al. [18] adopted numerical calculations to study the evolution of the stress field due to thick igneous rocks in coal seam mining and concluded that the stress anomalies due to the movement of thick igneous rocks were the power source of coal seam burst. Wang et al. [19] studied the effects of different mining stages of coal seams under thick magmatite on the upper overburden strata and the deformation pattern and damage mode of magmatite based on the elastic foundation thickplate theory and concluded that the deformation and breakage of thick magmatite were the main causes of the occurrence of dynamic disasters. The existing research results have provided useful guidance for the prevention and control of rock burst in working faces under thick hard strata, but there is less research on the burst mechanism of key working faces under thick hard strata. For the lack of theoretical guidance, the prevention and control of rock burst in key working faces have little effect. In this paper, taking the key working face under typical thick magmatite as the engineering background, a research on the mechanism of rock burst in key working faces under thick magmatite in deep mine was carried out, with the aim of providing reference for the prevention and control of rock burst under similar conditions.

\section{Proposition of the Key Working Face Concept}

The definition of the key working face is that the movement of the upper overburden strata, from working face 1 to working face $n$ under deep mining, does not develop to the earth surface, but is a movement of the overburden within a certain range above the coal seam, and the mine pressure or dynamic behavior in the mining of working faces is not obvious or strong. Only when the working face $n+1$ is mined, the large-scale overburden instability movement from working face $n+1$ to the earth surface leads to strong mine pressure behavior and even strong rock burst disaster during mining. This kind of working face is "key working face". During the mining in key working faces, due to the large movement range of overburden, its harm is much greater than that of general working faces.

The working face 1305 in a mine in Shandong has a depth of $980 \mathrm{~m}$, a width of $137 \mathrm{~m}$, an average coal seam thickness of $6.02 \mathrm{~m}$, and an average dip angle of $3^{\circ}$, with a burst potential. The mining situation around working face 1305 is shown in Figure 1(a). The northern part is goaf 1 with a width of $215 \mathrm{~m}$, and the southern part is goaf 2 with a total width of $410 \mathrm{~m}$. The overburden instability movement from the working face 1305 to the earth surface after mining has led to the overall instability type rock burst disaster. The release energy of the burst is $2.5 \times 10^{6} \mathrm{~J}$, with a magnitude of 2.3. The position suffering the burst is the working face and the advance headings on both sides, of which the track tunnel ahead is damaged $60 \mathrm{~m}$ and the transport tunnel ahead is damaged $40 \mathrm{~m}$, as shown in Figure 1(b). As per onsite analysis, the reason for more serious rock burst disaster occurred in working face 1305 is the formation of mining in the key working face.

\section{Measurement of Mine Pressure Behavior Characteristics during the Mining in Key Working Faces under Thick Magmatite in Deep Mine}

3.1. Project Overview. In the early stage of the construction of a mine in Shandong, with the aim of completing production tasks as soon as possible, they carried out the mining nearby, resulting in the formation of remaining coal seams in the later stage. In order not to waste resources and reduce mining costs, the remaining coal seams were designed as working face 12310, capable of one-time mining, as shown in Figure 2. The northwest part of working face 12310 is goaf 1 with a width of $135 \mathrm{~m}$, the southeast part is goaf 2 with a total width of $300 \mathrm{~m}$, and the northeast part is a large fault with a drop of $0-44 \mathrm{~m}$ and a dip angle of 75 degrees. The working coal seam is No. 3 coal seams, with a thickness of $3.1 \mathrm{~m}$ and a dip angle of $5-10^{\circ}$. The long wall fully mechanized method with high one-time mining is adopted, with the mining depth of $816 \mathrm{~m}$; the hardness of the coal seam is relatively high. As per the tendency of the rock burst tendency of the coal seam, No. 3 coal has a strong burst tendency (uniaxial compressive strength is about $19 \mathrm{MPa}$ ), and the roof and floor strata 


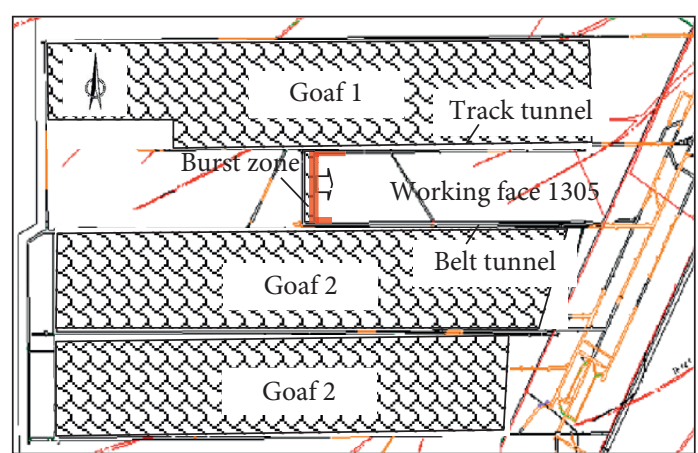

(a)
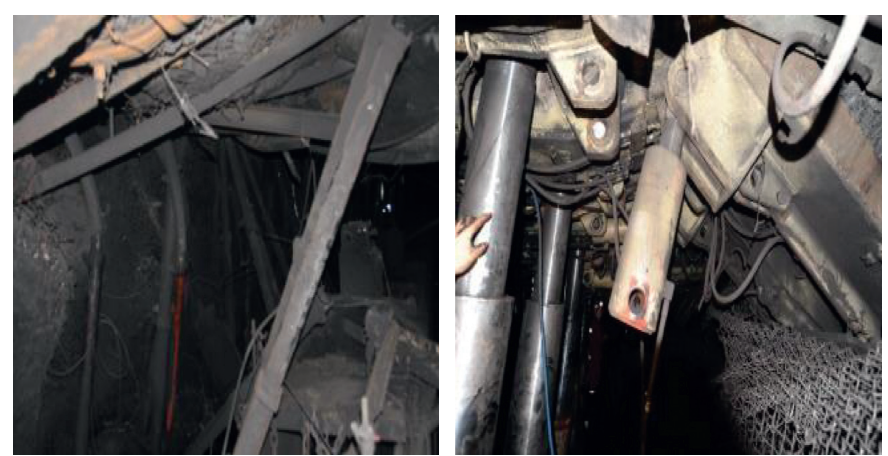

(b)

FIGURE 1: Overall instability and rock burst disaster of working face 1305. (a) Overall instability burst position of working face 1305 and (b) photos of rock burst disaster site.

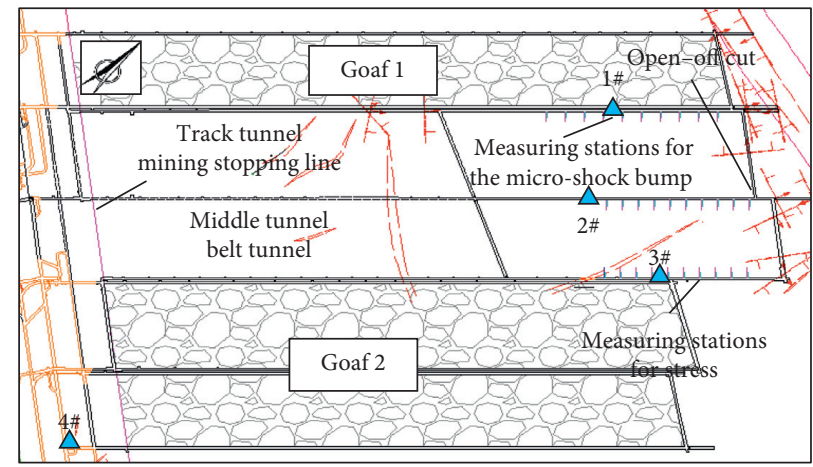

Figure 2: Mining plan of working face 12310.

have a weak burst tendency. As per the drilling data of attachment to working face 12310, thick magmatite with an average thickness of $125 \mathrm{~m}$ occurs about $250 \mathrm{~m}$ above the coal seam, and there are no other thick hard strata. As per the observation of rock movement on the earth surface, the subsidence of the earth surface is not obvious prior to the mining in working face 12310 , so it is estimated that the thick magmatite above it is still in a stable state.

\subsection{Identification of Key Working Face. As per the research} results of Luo et al. [20], before the strata are fully mined, the maximum fracture height of overburden in the working face is about $1 / 2$ of the width of the short side of the goaf. The width of goaf 1 and goaf 2 around working face 12310 is $135 \mathrm{~m}$ and $300 \mathrm{~m}$, respectively, the maximum fracture heights of the overburden in the two goafs are $67.5 \mathrm{~m}$ and $150 \mathrm{~m}$ respectively, while the distance between overlying thick magmatite and coal seam is $250 \mathrm{~m}$; therefore, the overburden movement in goafs on both sides of working face 12310 has not developed to the stratum of thick magmatite, which maintains stability before the mining. After working face 12310 is mined, the new goaf is connected with the goafs on both sides, and the overburden fracture continues to develop upward along the rock movement line. The total width of the three goafs is $736 \mathrm{~m}$, while the maximum fracture height of the overburden reaches $368 \mathrm{~m}$, which has exceeded the stratum where the thick magmatite is located, as shown in Figure 3. Now, the theoretical analysis method is adopted to judge whether the thick magmatite can continue to maintain stability at this time. As shown in Figure 3, the theoretical hanging arch length of thick magmatite is $736+2 \times 250$ cot $82^{\circ}=806 \mathrm{~m}$ (the rock movement angle $\alpha$ is $82^{\circ}$ ), which is much larger than the average thickness of $125 \mathrm{~m}$, so it can be regarded as the mounting beam. As per the theory of material mechanics, the calculation formula of limit span $L_{x}$ of mounting beams at both ends under the action of the upper uniform load is as follows:

$$
L_{x}=h \sqrt{\frac{2 \sigma_{T}}{q_{c}}} .
$$

The thickness $h$ of thick magmatite is $125 \mathrm{~m}$, and tensile strength $\sigma_{t}$ is $10.2 \mathrm{MPa}$. The stress of the horizontal "carrier" is not considered here for the time being, and the load on it could be estimated by simple static load; then, $q_{c}=\gamma_{\text {soft }} h_{\text {soft }}+\gamma_{\text {rock }}$ and $h=23 \times 441+26 \times 125=13.393 \mathrm{MPa}$. Taking the parameters into formula (1), the limit span $L_{x}$ of the thick magmatite beam is $154 \mathrm{~m}$, while the hanging arch length of thick magmatite is $806 \mathrm{~m}$, which is much larger than $154 \mathrm{~m}$, which is impossible. Therefore, the thick magmatite would suffer the fracture movement during the mining in working face 12310, and the controlled soft rock strata above it to the earth surface would move synchronously with it, which shows that working face 12310 has the characteristics of the key working face. 


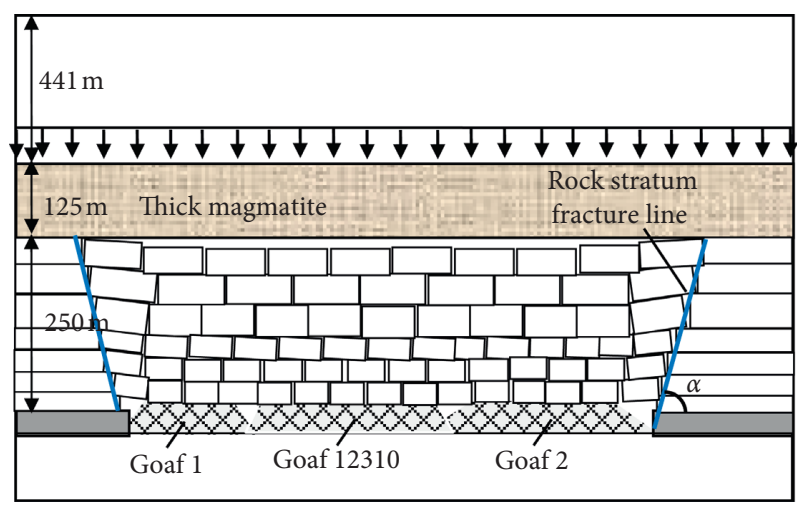

FIGURE 3: Inclining profile of working face 12310 after the mining.

3.3. Measurement of Mine Pressure Behavior Characteristics during the Mining in Key Working Faces under Thick Magmatite in Deep Mine. After the mining in key working face 12310 , the thick magmatite, as the overburden instability movement to the earth surface under the control of the main key stratum, leads to severe mine pressure behavior in key working face 12310. As per different causes, it can be divided into two types: the shock bump induced by the thick magmatite fracture and the instability loading.

3.3.1. Burst Hazard Induced by Shock Bump of Thick Magmatite Fracture. Figure 4 shows the daily energy change curve of the shock bump of thick magmatite during the mining in key working face 12310 from January 9, 2014, to January 2, 2015. As shown in the figure, the fracture of thick magmatite has occurred five times periodically, the first time is from January 9, 2014, to April 27, 2014 (the fracture span is $191 \mathrm{~m}$ ), the second time is from April 27, 2014, to May 24, 2014 (the fracture span is $97 \mathrm{~m}$ ), the third time is from May 24, 2014, to August 1, 2014 (the fracture span is $137 \mathrm{~m}$ ), the fourth time is from August 1, 2014, to October 20, 2014 (the fracture span is $141 \mathrm{~m}$ ), and the fifth time is from October 20, 2014, to December 15, 2014 (the fracture span is $130 \mathrm{~m}$ ). Although the daily size and duration of the energy released by the shock bump are different when each major fracture occurs, the burst hazard induced by the shock bump shows significant regularity: when the major fracture does not occur, the energy released by the shock bump is small and generally does not exceed the warning line; however, when the major fracture occurs, the daily energy released by the shock bump continues to rise, far exceeding the warning line until the end of it.

\subsubsection{Burst Hazard Caused by Instability Loading of Thick} Magmatite. As per the measurement of the micro-shock bump, the thick magmatite moves periodically during the mining in key working face 12310 . Under normal circumstances, during the mining in the working face to the thick magmatite fracture with span in each period, the thick magmatite gradually flexes and sinks under the action of its dead weight and upper load, resulting in the stress increase of the supporting coal body in front of the key working face.
Take the fracture movement of thick magmatite in the first period as an example for analysis. Figure 5 shows the measured results of the micro-shock bump and the stress of the advance coal body in the working face when thick magmatite is not flexed and sunk in the first period. As shown in Figure 5(a), the profile projection of the "fixed" working face of the micro-shock bump shows that the overburden movement height is about $147 \mathrm{~m}$, which does not reach the height where the thick magmatite is located. It remains stable within the mining range, mainly the static load of the rock strata from the upper part of the coal seam to the earth surface on the coal body in front of the working face, and the stress is generally not more than $15 \mathrm{MPa}$, with relatively small burst hazard, as shown in Figures 5(b) and 5(c).

Figure 6 shows the measured results of the micro-shock bump and the stress of the coal body in front of the working face when thick magmatite is flexed and enters into the loading stage in the first period. As shown in Figure 6(a), the projection of the "fixed" working face of the micro-shock bump shows that the overburden movement height in the working face has increased to $350 \mathrm{~m}$, which has exceeded the height where the thick magmatite is located. The thick magmatite and the controlled rock strata from its upper part to the earth surface flex and sink synchronously. The generated load is applied to the advance coal body, causing the stress to generally rise greatly. As shown in Figures 6(b) and 6(c), some measuring sites even get the results nearly $25 \mathrm{MPa}$, and the coal body in front of the working face has a great burst hazard on the whole.

As per the above on-the-spot measured results, it can be seen that, during the mining in the key working faces under thick magmatite in deep mine, the shock bump of the thick magmatite fracture has periodicity, and there is a danger of inducing rock burst when each shock bump occurs. In the process of mining close to its fracture span in each fracture period of thick magmatite in the key working face, the thick magmatite would flex and sink under the action of its dead weight and the controlled upper overburden strata load and give load to the supporting coal body in front of the working face, resulting in a sharp rise in stress and burst hazard.

\section{Evolution Process of the Overburden Structure under the Control of Thick Magmatite during the Mining in Key Working Faces of Deep Mine}

There is a certain relationship between the overburden structure evolution and mine pressure and dynamic behavior during the mining [21, 22]. There is thick magmatite in the upper overburden strata above key working face 12310, which is the main key strata controlling the overburden movement. It determines the distribution and movement characteristics of the overburden structure during the mining and then controls the behavior of mine pressure and dynamic pressure. In order to explore the mechanism of rock burst in key working faces under thick magmatite in deep mine, it is necessary to introduce the 


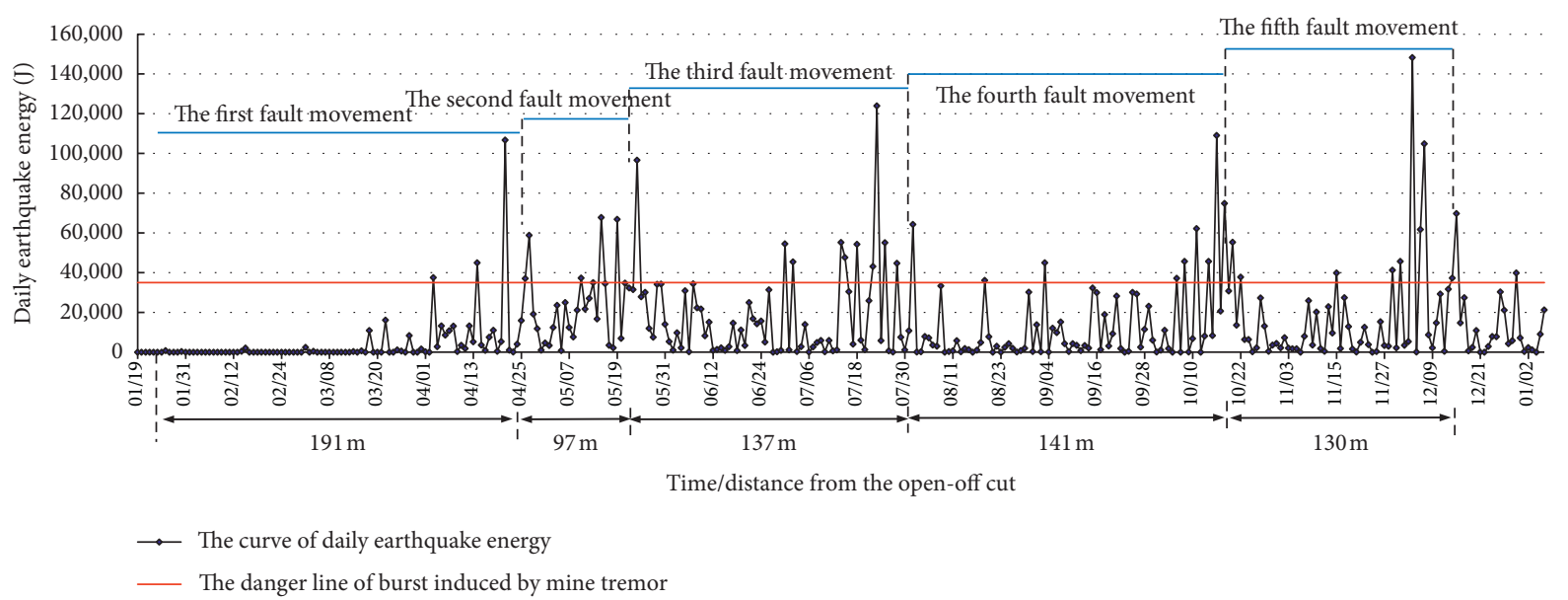

FIGURE 4: Curve of changes in daily shock bump energy of thick magmatite from January 9, 2014, to January 2, 2015.

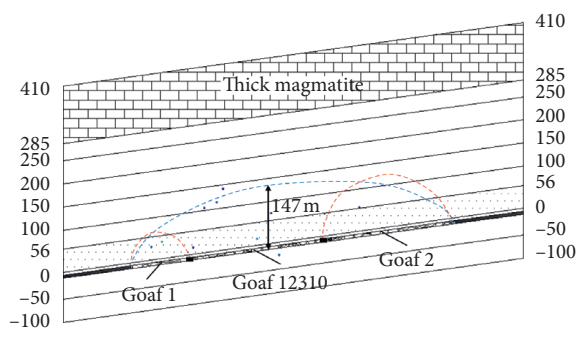

(a)

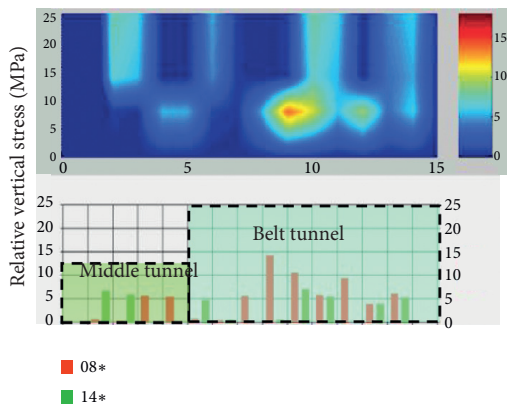

(b)

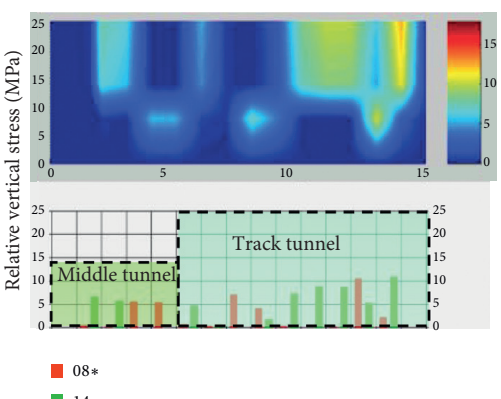

(c)

FIGURE 5: The distribution of micro-shock bump and the stress of the advance coal body in the working face when thick magmatite is not flexed and sunk in the first period. (a) Profile projection of the "fixed" working face of the micro-shock bump; (b) stress state of belt tunnel and partial middle tunnel; (c) stress state of track tunnel and partial middle tunnel.

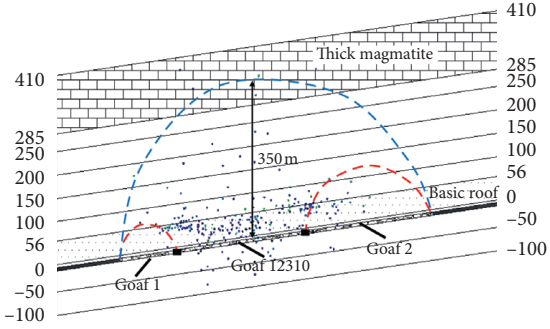

(a)

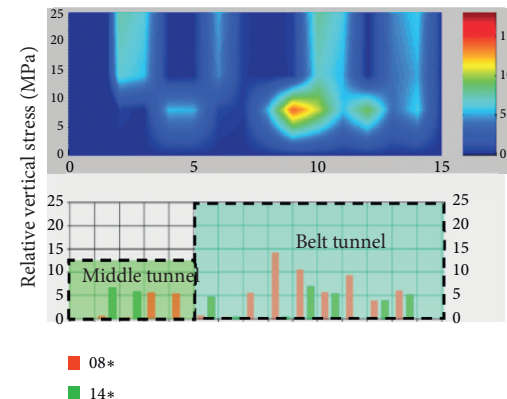

(b)

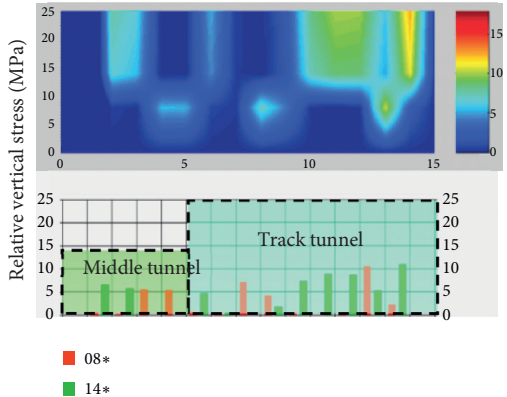

(c)

FIGURE 6: The distribution of micro-shock bump and the stress of the advance coal body in the working face when thick magmatite is flexed and enters into the loading stage in the first period. (a) Profile projection of the "fixed" working face of the micro-shock bump; (b) stress state of belt tunnel and partial middle tunnel; (c) stress state of track tunnel and partial middle tunnel.

theory of mine pressure to analyze the evolution process of the overburden structure under the control of thick magmatite during the mining in key working face 12310, thereby providing a basis for estimating the stress-causing disasters and further revealing the mechanism.
4.1. Discrimination of Structural Morphology after the Fracture of Thick Magmatite. Based on the theory of mine pressure, cantilever beam structure or masonry beam structure is formed after the fracture of the key upper overburden of goaf, and the magnitude of stress-causing 
disasters generated by different structures is different. As per the research results of Qian et al. [23], the formed structure after the fracture of the key upper overburden of goaf mainly depends on whether the rotation amount of the fractured rock block in the key stratum exceeds the maximum rotation amount of its stable structure. The rotation amount $\Delta_{p}$ of the fractured rock block in the key stratum is estimated as formula (2), and the maximum rotation amount $\Delta_{x}$ required to form the cantilever beam structure is estimated as formula (3). When there is $\Delta_{p} \geq \Delta_{\mathrm{x}}$, the cantilever beam structure is formed, and vice versa, the masonry beam structure is formed.

$$
\Delta_{p}=h_{c}-(k-1) h_{v}
$$

where $h_{c}$ is the mining height, $k$ is the comprehensive fragmentation expansion coefficient of collapsed strata, and $h_{v}$ is the vertical height between the key stratum and the coal seam.

$$
\Delta_{x}=h_{g}-L_{p} \sqrt{\frac{2 q_{c}}{[\sigma]}}
$$

where $L_{p}$ and $[\sigma]$ are the fracture span of key stratum and the compressive strength of fractured rock blocks, respectively.

Now, the structural types of fractured rock beams of thick magmatite during mining in working faces are analyzed as per the geology and mining conditions of key working face 12310 . The mining height of the coal seam is expressed as $h_{c}=3.1 \mathrm{~m}, k=1.01, h_{v}=250 \mathrm{~m}$, and take them into formula (2) and obtain $\Delta_{p}=0.6 \mathrm{~m}$. As for the thick magmatite, average fracture span $L_{p}=139.2 \mathrm{~m}$ (according to the measurement for the micro-shock bump), $q_{c}=13.393 \mathrm{MPa}, \quad \gamma_{g}=26 \mathrm{kN} / \mathrm{m}^{3}, \quad h_{g}=125 \mathrm{~m}, \quad[\sigma]=$ $33.56 \mathrm{MPa}$, and take them into formula (3) and obtain $\Delta_{x}=0.64 \mathrm{~m}$. It can be seen that $\Delta_{p}<\Delta_{x}$, so during the mining in key working face 12310 , a stable masonry beam structure can be formed after the fracture of the thick magmatite. In the following, the overburden movement model under the control of thick magmatite during the mining in key working face 12310 is studied, and the stress-causing disasters induced by overburden movement are estimated accordingly.

\subsection{Evolution of the Overburden Structure under the Control of} Thick Magmatite during the Mining in Key Working Faces. As per the measurement of micro-shock bump, the average fracture span of the thick magmatite is $139.2 \mathrm{~m}$, the theoretical length of the thick magmatite along the inclination of the working face is $806 \mathrm{~m}$ and the natural average thickness of the thick magmatite is $125 \mathrm{~m}$ after the mining in key working face 12310. And the length is much larger than the cross-sectional size; therefore, the horizontal fracture of the thick magmatite can be regarded as the periodic fracture of the beam.

After the mining from the open-off cut in key working face 12310, the low soft rock stratum above the coal seam collapses stratum by stratum. As the bending rigidity is far less than that of the thick magmatite, the separation is gradually formed between the low soft rock stratum and the thick magmatite, resulting in the slow flexion and subsidence of the thick magmatite under the action of its dead weight and the controlled upper overburden strata load. However, it is still in a suspended state, showing an "inverted U-shape", as shown in Figure 7. With the continuous mining in key working faces, the first fracture occurs when the thick magmatite reaches the limit fracture span, accompanied by shock bump. As shown in Figure 8, after the initial fracture, one end of the thick magmatite block rotates and sinks, and the other end is hinged with the uncollapsed rock beam to form an "inverted V-shaped" structure. After that, with the continuous mining in key working faces, the thick magmatite enters the state of periodic movement. The thick magmatite separates from the lower low strata and forms a suspended roof. Under its own strength and the support of the lower key working face block, the thick magmatite hinges with the fractured rock block of the thick magmatite behind the goaf to form a periodic "inverted V-shaped" structure. With the increase in the mining range, the thick magmatite undergoes periodic movement as "suspension $\longrightarrow$ flexion $\longrightarrow$ fracture".

\section{Analysis on Mechanism of Rock Burst in Key Working Faces under Thick Magmatite in Deep Mine}

5.1. Estimation of Stress-Causing Disasters Bearing by Key Working Face Blocks in Periodic Movement of the Thick Magmatite. As per the evolution of the overburden structure under the control of thick magmatite during the mining in key working faces, the periodic fracture of the thick magmatite is caused by the mining in corresponding key working face blocks. The key working face block bears the dynamic load generated by the movement caused by the periodic fracture of the thick magmatite. As per different sources, it can be divided into the dynamic load caused by the slow subsidence of the "inverted V-shaped" structure of the thick magmatite beam, the load caused by the shock bump from the fracture of the thick magmatite beam, the dynamic load caused by the continuously collapsed strata between the key working face block and the thick magmatite, and the dynamic load caused by the suspended strata in the goaf behind the key working face blocks.

5.1.1. Estimation of Dynamic Load Caused by Slow Subsidence of "Inverted V-Shaped" Structure of the Thick Magmatite Beam. The dynamic bearing model of the corresponding key working face blocks that lead to periodic fracture of the thick magmatite is established as shown in Figure 9. As shown in the figure, in each fracture movement period of the thick magmatite, as the directing length of the bearing block of the key working face gradually decreases, the lower support of the "-" in the "inverted V-shaped" structure of the thick magmatite beam gradually collapses, resulting in the slow subsidence of the "inverted V-shaped" structure, and the structural load is gradually applied to the bearing block of the key working face through the lower 


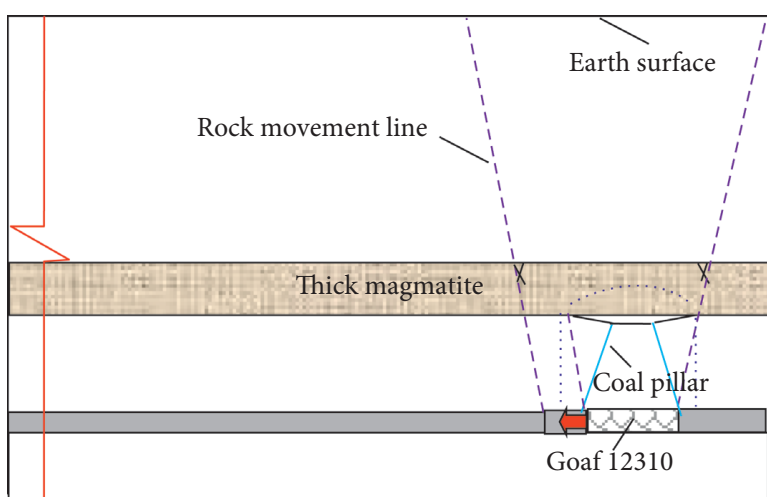

(a)

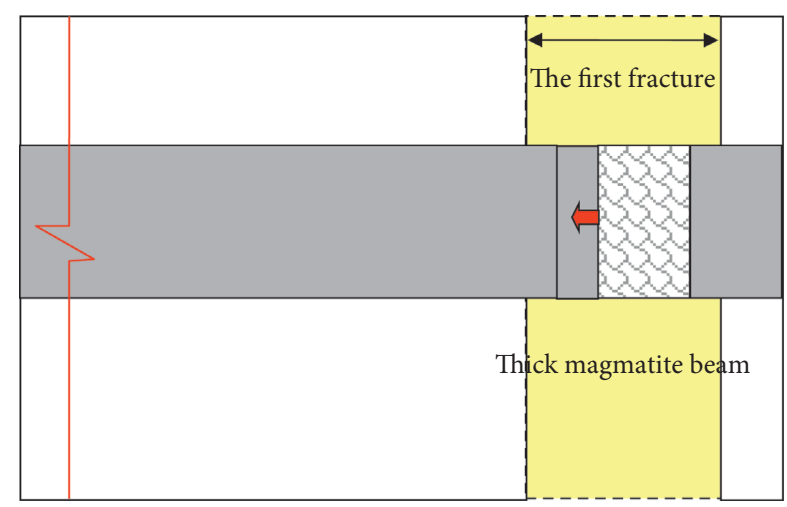

(b)

Figure 7: Overburden structure before the first fracture of the thick magmatite. (a) Profile along the direction of the working face and (b) plane projection.

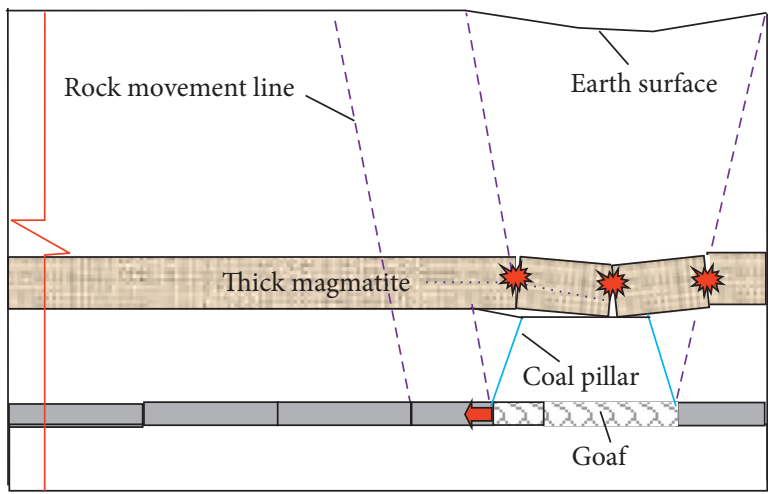

(a)

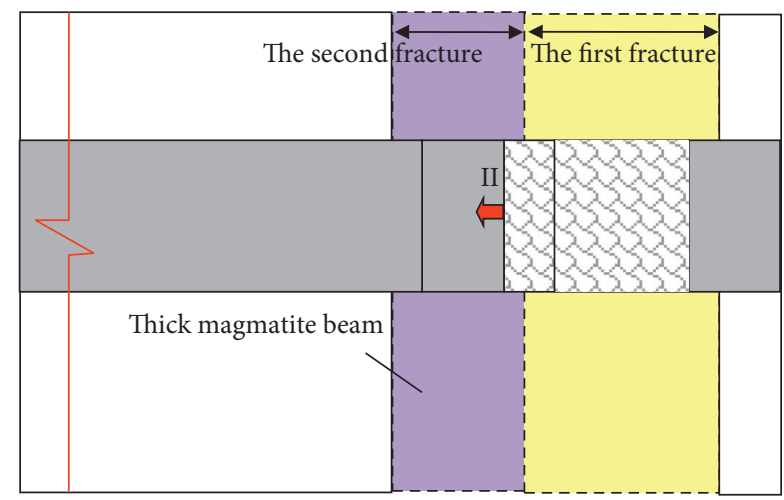

(b)

FIGURE 8: Overburden structure before the second fracture of the thick magmatite. (a) Profile along the direction of the working face and (b) plane projection.

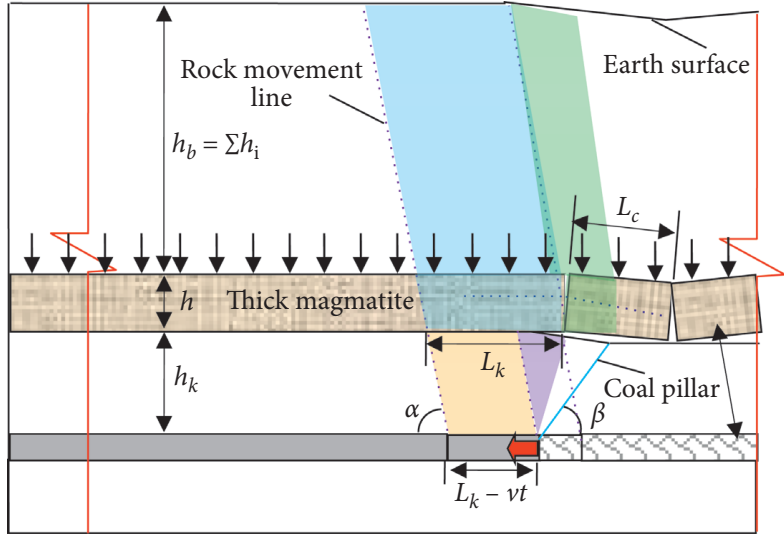

(a)

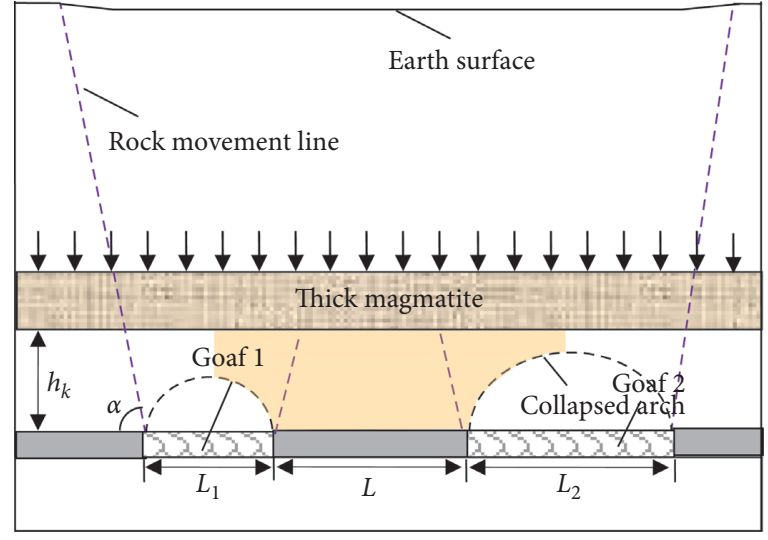

(b)

FIGURE 9: Dynamic bearing model of corresponding key working face blocks in periodic fracture of thick magmatite. (a) Profile along the direction of the working face and (b) profile along the inclination of the working face. 
supporting rock body. It can be assumed that the coal and rock on both sides of the large goaf in Figure 9 are rigid bodies, and the two ends of the thick magmatite beam can be regarded as they are fixed in the rigid rock bodies. If the supporting force of the key working face block to the thick magmatite beam through the upper rock strata to the bottom of the thick magmatite beam is $F_{\mathrm{d}}$, the simplified mechanical model of the thick magmatite beam is shown in Figure 10. Taking the equilibrium conditions $\sum F=0$ and $\sum M=0$ as the origin coordinate 0 of the thick magmatite beam, the concentrated forces at the two fixed ends of the thick magmatite beam are obtained as follows:

$$
\left.\begin{array}{l}
R_{1}=\frac{q L_{k}\left(2 h_{k} \cot \alpha+\left(L_{1}+L_{2}+L\right)\right)}{2}-\frac{F_{d}\left(2 h_{k} \cot \alpha+2 L_{2}+L\right)}{4 h_{k} \cot \alpha+2 L_{1}+2 L_{2}+2 L} \\
R_{2}=\frac{q L_{k}\left(2 h_{k} \cot \alpha+\left(L_{1}+L_{2}+L\right)\right)}{2}-\frac{F_{d}\left(2 h_{k} \cot \alpha+2 L_{1}+L\right)}{4 h_{k} \cot \alpha+2 L_{1}+2 L_{2}+2 L}
\end{array}\right\}
$$

where $L_{k}$ is the fractured length of the thick magmatite beam in this period; $L$ is the inclined length of the key working face; $L_{1}$ is the width of goaf $1 ; L_{2}$ is the width of goaf $2 ; h_{k}$ is the vertical height between the thick magmatite and the coal seam; $q$ is the dead weight of the "inverted V-shaped" structure of the thick magmatite beam and the load of the upper overburden strata (strata of blue and green zone in Figure 9), $q=\left[\left(2 h_{k}+h_{b}+\right.\right.$ h) cot $\left.\quad \alpha+L_{1}+L_{2}+L\right] \gamma h_{b}\left(2 L_{k}+L_{c}\right) \sin \alpha / 2 L_{k}\left(2 h_{k} \cot \alpha\right.$ $\left.+L_{1}+L_{2}+L\right)$ ), where $h_{b}$ is the vertical height from the top of the thick magmatite to the earth surface; $L_{c}$ is the fractured length of the previous period of the thick magmatite beam; and $\gamma$ is the average volume weight of the strata.
As per the theory of elasticity, the approximate equation of beam bending deformation is as follows:

$$
\frac{\mathrm{d}^{2} y}{\mathrm{~d} x^{2}}=\frac{M(x)}{E I}
$$

where $E$ is the elastic modulus of the thick magmatite beam and $I$ is the cross section inertia moment of the thick magmatite beam.

The bending moment equation $M(x)$ when the thick magmatite beam is within $0 \leq x \leq h k \cot \alpha+L 1+L / 2$ is as follows:

$$
M(x)=\frac{q L_{k} x^{2}}{2}-\left[\frac{q L_{k}\left(2 h_{k} \cot \alpha+L_{1}+L_{2}+L\right)}{2}-\frac{F_{d}\left(2 h_{k} \cot \alpha+2 L_{2}+L\right)}{4 h_{k} \cot \alpha+2 L_{1}+2 L_{2}+2 L}\right] x .
$$

If the deflection and turn angle of the thick magmatite beam at the fixed ends are both 0 , the boundary conditions are as follows:

$$
\left.\frac{\mathrm{d} M(x)}{\mathrm{d} x}\right|_{x=0}=0,\left.\quad M(x)\right|_{x=0}=0 .
$$

The deflection equation of the thick magmatite beam can be obtained by integrating both formula (5) and formula (6) and then taking the boundary condition (7), which is as follows:

$$
y=\frac{1}{E I}\left\{\frac{q L_{k}}{24} x^{4}-\left[\frac{q L_{k}\left(2 h_{k} \cot \alpha+L_{1}+L_{2}+L\right)}{2}-\frac{F_{d}\left(2 h_{k} \cot \alpha+2 L_{2}+L\right)}{4 h_{k} \cot \alpha+2 L_{1}+2 L_{2}+2 L}\right] \frac{x^{3}}{6}\right\}
$$

Taking $x=h_{k} \cot \alpha+L_{1}+L / 2$ into formula (8), the deflection of the thick magmatite beam under dead weight and the upper overburden strata load is as follows:

$$
\left.y\right|_{x=h_{k} \cot \alpha+L_{1}+(L / 2)}=\frac{1}{E I}\left\{\begin{array}{c}
\frac{q L_{k}}{24}\left(h_{k} \cot \alpha+L_{1}+\frac{L}{2}\right)^{4}-\left[\frac{q L_{k}\left(2 h_{k} \cot \alpha+L_{1}+L_{2}+L\right)}{2}-\frac{F_{d}\left(2 h_{k} \cot \alpha+2 L_{2}+L\right)}{4 h_{k} \cot \alpha+2 L_{1}+2 L_{2}+2 L}\right] \\
\frac{\left(h_{k} \cot \alpha+L_{1}+L / 2\right)^{3}}{6}
\end{array}\right\} .
$$




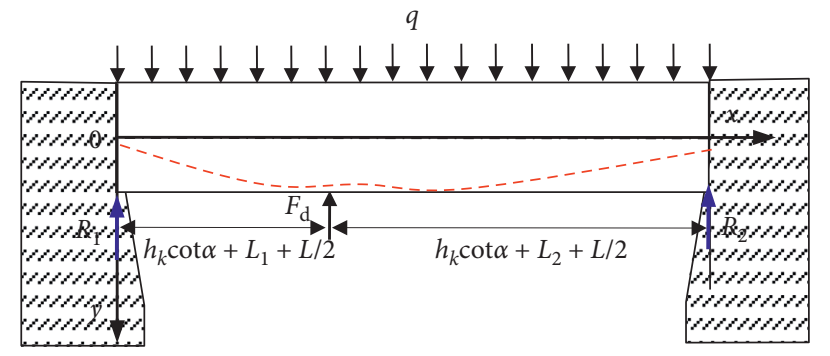

FIGURE 10: Simplified mechanical model of thick magmatite beam.

As per formula (9), it can be seen that the deflection of the thick magmatite beam at $x=h_{k} \cot \alpha+L_{1}+L / 2$ has a functional relationship with the supporting force $F_{d}$ of the key working face block to the thick magmatite beam. The deflection of the thick magmatite beam can be obtained from the measurement of the earth surface. If its falling interval is $[0, w]$, then each falling value $u$ in this interval corresponds to the loading value of the thick magmatite beam on the key working face block (the reaction force of the supporting force $F_{d}$ ).

As per the theory of material mechanics, if the bending deformation is too large, the brittle material of the thick magmatite beam would be fractured with tension, and the tensile fracture position would occur at the maximum bending moment. Make a derivation for formula (6) and the maximum bending moment of thick magmatite beam can be obtained as follows: $M^{\prime}(x)=0$.

$$
\begin{aligned}
\left.M_{\max }\right|_{x=z} & =-\frac{\left[q L_{k}\left(2 h_{k} \cot \alpha+L_{1}+L_{2}+L\right) / 2-F_{d}\left(2 h_{k} \cot \alpha+2 L_{2}+L\right) / 4 h_{k} \cot \alpha+2 L_{1}+2 L_{2}+2 L\right]^{2}}{2 q L_{k}}, \\
z & =\frac{\left[\left(q L_{k}\left(2 h_{k} \cot \alpha+L_{1}+L_{2}+L\right) / 2\right)-\left(F_{d}\left(2 h_{k} \cot \alpha+2 L_{2}+L\right) / 4 h_{k} \cot \alpha+2 L_{1}+2 L_{2}+2 L\right)\right]}{q L_{k^{\circ}}} .
\end{aligned}
$$

The tensile stress $\sigma_{\max }$ at the maximum bending moment of the thick magmatite beam is as follows:

$$
\left.\sigma_{\max }\right|_{x=z}=\frac{M_{\max }}{W_{z}} \frac{3\left[q L_{k}\left(2 h_{k} \cot \alpha+L_{1}+L_{2}+L\right) / 2-F_{d}\left(2 h_{k} \cot \alpha+2 L_{2}+L\right) / 4 h_{k} \cot \alpha+2 L_{1}+2 L_{2}+2 L\right]^{2}}{q L_{k}^{2} h^{2}},
$$

where $W_{z}$ is the bending section coefficient of the thick magmatite beam.

If the ultimate tensile strength of the thick magmatite beam is $\left[\sigma_{p}\right]$, and there is $\sigma_{\max } \geq\left[\sigma_{\mathrm{p}}\right]$, the thick magmatite beam will be fractured.

\subsubsection{Estimation of Shock Bump Dynamic Load of Fracture in} the Thick Magmatite Beam. As per the mining practice and research, the dynamic load effect is often caused by the shock bump from the fracture in the high and thick hard rock when the mining is in the working face [11-14]. After the analysis of Figure 9, during the periodic fracture of the thick magmatite beam under the action of dead weight and the upper load, bending deformation (the bending moment taking into effect) occurs on one side in the vertical direction and torsional deformation (torque taking into effect) occurs on the other side in the horizontal direction. The strain energy $U$ generated during the deformation process is stored in the rock body, and its expression is as follows: 


$$
\begin{aligned}
& U=U_{h}+U_{l} \\
& U_{h}=L_{k} q \int_{0}^{L_{1}+L_{2}+L+2 h_{k} \cot \alpha} y \mathrm{~d} x \\
& y=\frac{1}{E I}\left\{\frac{q L_{k}}{24} x^{4}-\left[\frac{q L_{k}\left(2 h_{k} \cot \alpha+L_{1}+L_{2}+L\right)}{2}-\frac{F_{d}\left(2 h_{k} \cot \alpha+2 L_{2}+L\right)}{4 h_{k} \cot \alpha+2 L_{1}+2 L_{2}+2 L}\right] \frac{x^{3}}{6}\right\} \\
& U_{l}=\left(L_{1}+L_{2}+L+2 h_{k} \cot \alpha\right) \int_{0}^{L_{k}} \frac{\theta \pi x}{180} q \mathrm{~d} x
\end{aligned}
$$

where $U_{h}, U_{l}$, and $\theta$ are, respectively, the vertical bending deformation energy, horizontal torsional deformation energy, and rotation angle along the direction of the thick magmatite beam.

As per the research of relevant scholars, most of the energy released by the fracture of thick and hard rock is converted into heat energy by taking into effect on surrounding rock, and only $1 \%-10 \%$ [24] of the energy is converted into vibration waves to be spread around. The thick magmatite beam has a large inclining hanging roof length and would fracture many times after reaching the tensile limit in the process of subsidence, bending, and torsion. Only a small amount of energy could be converted into vibration waves to propagate around each fracture. In addition, the rock strata are heterogeneous bodies, and the vibration waves would be further dissipated in the process of transmission to the key working face blocks. It can be assumed that the thick magmatite beam passes through $N$ fractures in a period and the energy released by each fracture is equal, and the approximate expression of the energy $U_{f}$ finally received by the key working face block each time is as follows:

$$
U_{f}=\frac{\mu U}{N} r^{-\delta},
$$

where $r$ is the distance from the seismic focus to the working face and $\delta$ is an energy attenuation coefficient, which is related to the seismic focus energy and the nature of rock strata. $\mu$ is the conversion coefficient that the energy released by a single fracture of a thick magmatite beam is converted into vibration wave.

As per the theory of physics, the dynamic load $F_{a}$ generated by the key working face block after receiving energy $U_{f}$ can be obtained as follows:

$$
\left.\begin{array}{l}
F_{a}=m a \\
v_{a}=a T_{a} \\
U_{f}=\frac{1}{2} m v_{a}^{2} \\
m=\rho\left(L_{k}-v t\right) L h_{c}
\end{array}\right\},
$$

where $a$ is the acceleration generated by the key working face block; $\rho$ is the density of coal body; and $T_{a}$ and $v_{a}$ are, respectively, the time and velocity of coal body affected by vibration wave in key working face blocks.

Integrating formulas (12) (14), the expression of dynamic load $F_{a}$ generated by the shock bump from the thick magmatite beam fracture on the key working face block is obtained as follows:

$$
F_{a}=\frac{1}{T_{a}} \sqrt{\frac{\rho\left(L_{k}-v t\right) L h_{c} \mu r^{-\delta} q L_{k}\left(L_{1}+L_{2}+L+2 h_{k} \cot \alpha\right)}{4 N}\left[\begin{array}{c}
-\frac{q L_{k}\left(L_{1}+L_{2}+L+2 h_{k} \cot \alpha\right)^{4}}{10 E I} \\
+\frac{F_{d}\left(2 h_{k} \cot \alpha+2 L_{2}+L\right)\left(L_{1}+L_{2}+L+2 h_{k} \cot \alpha\right)^{2}}{6 E I}+\frac{L_{k} \theta \pi}{45}
\end{array}\right]}
$$


where

$$
F_{d}=\frac{\left(2 h_{k} \cot \alpha+L_{1}+L_{2}+L\right)}{2 h_{k} \cot \alpha+2 L_{2}+L}\left[\frac{12 E I u}{\left(h_{k} \cot \alpha+L_{1}+L / 2\right)^{3}}-\frac{q L_{k}}{2}\left(h_{k} \cot \alpha+L_{1}+\frac{L}{2}\right)+q L_{k}\left(2 h_{k} \cot \alpha+L_{1}+L_{2}+L\right)\right] .
$$

5.1.3. Dynamic Load Estimation of Collapsed Strata between Key Working Face Blocks and the Thick Magmatite. As shown in Figure 9, the lower supporting rock (strata of the yellow zone in Figure 9) of the "-" in the "inverted V-shaped" structure of the thick magmatite beam gradually collapses with the continuous mining in the key working face block, with the load of the noncollapsed strata applied to the key working face block, and the estimation formula of the weight $Q_{\mathrm{d}}$ of these strata is as follows:

$$
Q_{d}=\gamma\left[\left(\frac{L_{1}+L_{2}}{2}+L\right) h_{k}-\frac{\pi\left(L_{1}^{2}+L_{2}^{2}\right)}{16}\right]\left(L_{k}-v t\right) \sin \alpha,
$$

where $v$ and $t$ are the speed and time of the mining in key working faces, respectively.

5.1.4. Estimation of Dynamic Load Generated by the Suspended Strata in Goaf behind Key Working Face Blocks.
After the mining is carried out from the open-off cut in key working face 12310, the overburden above the coal seam collapses from the low position to the high one stratum by stratum. In general, the collapsed strata are fully fractured, while the rock strata near the key working face block cannot fully collapse due to the coal body boundary effect. The rock strata located between the gangue contact line and the rock movement line form cantilever rock strata, which reach dynamic balance after developing to the thick magmatite. Half of its weight is carried by the key working face block (strata of the purple zone in Figure 9), and the estimation formula is as follows:

$$
Q_{k}=\frac{(\cot \alpha+\cot \beta) h_{k}^{2} \gamma L}{4} .
$$

Integrating formulas (9), (17), and (18), the average stress $P_{j}$ of the key working face block under flexural loading of the thick magmatite beam is obtained as follows:

$$
P_{j}=\frac{1}{\left(L_{k}-v t\right) L}\left\{\begin{array}{c}
\frac{\left(2 h_{k} \cot \alpha+L_{1}+L_{2}+L\right)}{2 h_{k} \cot \alpha+2 L_{2}+L}\left[\frac{12 E I u}{\left(h_{k} \cot \alpha+L_{1}+L / 2\right)^{3}}-\frac{q L_{k}}{2}\left(h_{k} \cot \alpha+L_{1}+\frac{L}{2}\right)+q L_{k}\left(2 h_{k} \cot \alpha+L_{1}+L_{2}+L\right)\right]+\gamma \\
{\left[\left(\frac{L_{1}+L_{2}}{2}+L\right) h_{k}-\frac{\pi\left(L_{1}^{2}+L_{2}^{2}\right)}{16}\right]\left(L_{k}-v t\right) \sin \alpha+\frac{(\cot \alpha+\cot \beta) h_{k}^{2} \gamma L}{4}}
\end{array}\right\} .
$$

Integrating formulas (9), (15), (17), and (18), the average stress $P_{D}$ of the key working face block affected by the shock bump from the thick magmatite beam fracture is obtained as follows:

$$
P_{D}=\frac{1}{\left(L_{k}-v t\right) L}\left\{\begin{array}{c}
\left.\frac{\left(2 h_{k} \cot \alpha+L_{1}+L_{2}+L\right)}{2 h_{k} \cot \alpha+2 L_{2}+L}\left[\begin{array}{c}
\frac{12 E I u}{\left(h_{k} \cot \alpha+L_{1}+L / 2\right)^{3}}-\frac{q L_{k}}{2}\left(h_{k} \cot \alpha+L_{1}+\frac{L}{2}\right)+ \\
q L_{k}\left(2 h_{k} \cot \alpha+L_{1}+L_{2}+L\right)
\end{array}\right]+\gamma\left[\left(\frac{L_{1}+L_{2}}{2}+L\right) h_{k}-\frac{\pi\left(L_{1}^{2}+L_{2}^{2}\right)}{16}\right]\left(L_{k}-v t\right) \sin \alpha+\frac{(\cot \alpha+\cot \beta) h_{k}^{2} \gamma L}{4}\right] \\
\left.+\frac{1}{T_{a}} \sqrt{\frac{\rho\left(L_{k}-v t\right) L h_{c} \mu r^{-\delta} q L_{k}\left(L_{1}+L_{2}+L+2 h_{k} \cot \alpha\right)}{4 N}\left[\begin{array}{c}
-\frac{q L_{k}\left(L_{1}+L_{2}+L+2 h_{k} \cot \alpha\right)^{4}}{10 E I} \\
+\frac{F_{d}\left(2 h_{k} \cot \alpha+2 L_{2}+L\right)\left(L_{1}+L_{2}+L+2 h_{k} \cot \alpha\right)^{2}}{6 E I} \\
+\frac{L_{k} \theta \pi}{45}
\end{array}\right.}\right\}
\end{array}\right\}
$$


5.2. Analysis of the Dynamic Support Strength of Key Working Face Block in Periodic Movement of the Thick Magmatite. In order to facilitate the calculation and apply the law to the general situation, the existence of the middle tunnel of key working face 12310 is ignored here, and the upper support pressure distribution during the mining in key working face blocks under the thick magmatite is shown in Figure 11. With the increase of distance from goaf or tunnel edge, the support pressure decreases as per negative exponential curve [23], forming a plastic zone and elastic zone from coal body edge to the deep part in turn under high stress. The plastic zone is under one-way or two-way stress, with weak bearing capacity. However, for the fact that the deep elastic zone is constrained by the "clamping" effect of the coal body in the surrounding plastic zone and the roof-floor strata, the coal body is in a three-dimensional stress state with high strength, which is the main bearing body of the key working face block. With the gradual decrease of the directing length of the key working face block, the support pressure of the key working face block and the elastic-plastic zone caused by it is redistributed. When the elastic zone is small, the overall support strength of the key working face block is insufficient, and the coal body can be destroyed and would be unstable. The compressive coefficient of the coal body in the elastic zone is $f_{\text {max }}$, and the compressive coefficient of the coal body in the plastic zone is $f_{\text {min }}$. As per the two-zone constraint theory of Wilson [25], the dynamic support strength $R_{D}$ during the mining in the key working face block can be approximately expressed as follows:

$$
R_{D}=\bar{\varphi} \sigma_{C}=\left[\frac{\left(L_{k}-v t-x_{1}\right) x_{2}+\left(L_{k}-v t-x_{1}\right) x_{3}+L x_{1}}{L\left(L_{k}-v t\right)} \cdot \varphi_{\min }+\frac{\left(L_{k}-v t-x_{1}\right)\left(L_{k}-x_{2}-x_{3}\right)}{L\left(L_{k}-v t\right)} \varphi_{\max }\right] \sigma_{c}
$$

where $\bar{\varphi}$ is the comprehensive compressive coefficient of coal body and $\sigma_{c}$ is the uniaxial compressive strength of coal body. $x_{i}$ $(i=1,2$, or 3$)$ is the width of the plastic zone. As per the limit equilibrium theory, the width of the plastic zone [23] $X_{i}=(m / 2 \vartheta f) \ln \left(K_{i} \gamma H+C \cot \phi / \vartheta C \cot \phi\right), K_{i}$ is the stress concentration factor $(i=1,2$, or 3$), P$ is the tunnel wall support resistance, $m$ is the thickness of the mined coal seam, $C$ is the cohesion of the coal body, $\varphi$ is the internal friction angle of the coal body, $f$ is the friction coefficient of the contact surface between the coal seam and the roof-floor strata, $\xi$ is the triaxial stress coefficient, and $\xi=(1+\sin \varphi) /(1-\sin \varphi)$.

\subsection{Mechanism of Rock Burst in Key Working Faces under} Thick Magmatite in Deep Mine. Overall instability burst often occurs in the key working faces under thick magmatite in deep mine, and the bearing capacity and load of the key working face block, which causes the periodic fracture of thick magmatite, are constantly changing during the mining in the working face. The full rock burst would occur once the instability occurs in the dynamic confrontation of "loading-bearing". As per different burst sources, it can be divided into flexural loading burst of thick magmatite (type I) and shock bump burst of thick magmatite fracture (type II).

5.3.1. The Flexural Loading Burst of Thick Magmatite (Type I). As for the periodical fracture of thick magmatite during the mining in key working faces, each fracture is caused by the mining in the corresponding key working face blocks. The load acting on the key working face block increases with the increase of the suspended length of thick magmatite. When the average stress $P_{j}$ acting on the key working face block exceeds its comprehensive support strength RD, type I overall instability burst would occur. The required mechanical conditions are as follows:

$$
\frac{P_{j}}{R_{D}}>1 \text { and } \sigma_{\max }<\left[\sigma_{p}\right]
$$

5.3.2. The Shock Bump Burst of Thick Magmatite Fracture (Type II). With the continuous miming of the key work face block, when the bending and subsidence of the thick magmatite reach the ultimate tensile strength, the thick magmatite would fracture and a shock bump would occur. The released elastic energy is partially converted into vibration shock wave, which is transmitted to the key working face block to form dynamic load, which would be superimposed with the existing stress of the key working face block. When the superimposed average stress PD exceeds the comprehensive support strength RD of the key working face block, type II overall instability burst would occur. The required mechanical conditions at this time are as follows:

$$
\frac{P_{D}}{R_{D}}>1 \text { and } \sigma_{\max } \geq\left[\sigma_{p}\right]
$$

As per the monitoring on the micro-shock bump, although the fracture spans of the thick magmatite are different in different periods, which in the same period can be considered as fixed, and the directing length corresponding to the critical instability burst of the key working face block is also fixed. The above analysis shows that the comprehensive support strength of the key working face block is mainly related to the distribution of elastic zones (Figure 11). Then, under the condition that the directing length of the key working face block is unchanged during the critical instability burst, the comprehensive support strength of the key working face block can be determined by its width. Integrating formulas (19)-(23) and taking the limit equilibrium condition, the determination formula of the limit width $L_{\mathrm{h}}$ of the key working face without the overall instability burst is obtained as follows: 


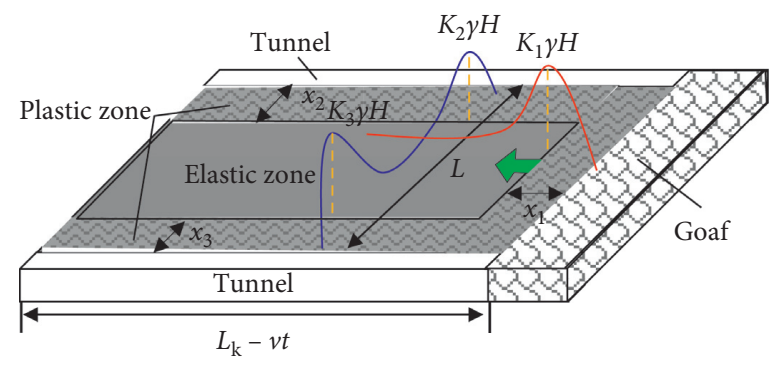

FIGURE 11: Dynamic distribution of key working face block elastic-plastic zone and support pressure.

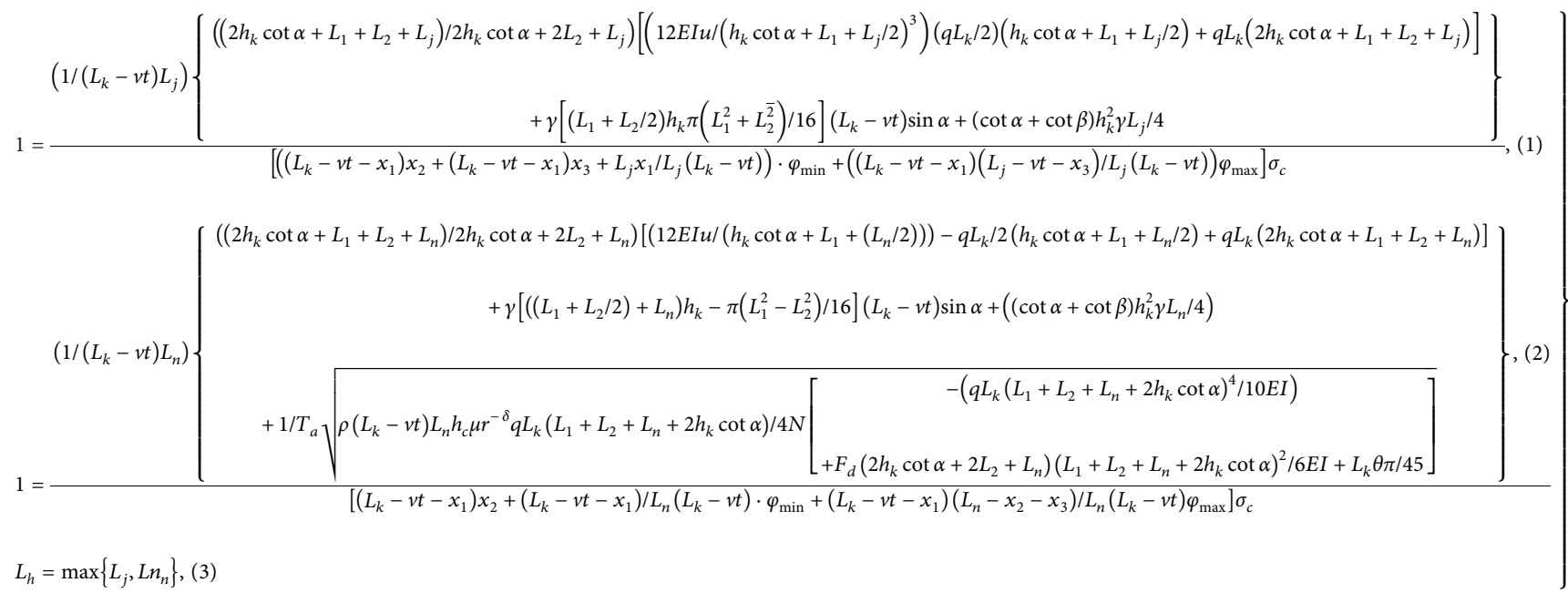

where $L_{j}$ and $L_{n}$ are the inclined lengths of critical instability of key working face blocks under $P_{j}$ and $P_{D}$ conditions, respectively.

In formula (1),

$$
q=\frac{\left[\left(2 h_{k}+h_{b}+h\right) \cot \alpha+L_{1}+L_{2}+L_{j}\right] \gamma h_{b}\left(2 L_{k}+L_{c}\right) \sin \alpha}{2 L_{k}\left(2 h_{k} \cot \alpha+L_{1}+L_{2}+L_{j}\right)}
$$

In formula (2),

$$
\begin{aligned}
q & =\frac{\left[\left(2 h_{k}+h_{b}+h\right) \cot \alpha+L_{1}+L_{2}+L_{j n}\right] \gamma h_{b}\left(2 L_{k}+L_{c}\right) \sin \alpha}{2 L_{k}\left(2 h_{k} \cot \alpha+L_{1}+L_{2}+L_{n}\right)}, \\
F_{d} & =\frac{\left(2 h_{k} \cot \alpha+L_{1}+L_{2}+L_{n}\right)}{2 h_{k} \cot \alpha+2 L_{2}+L_{n}}\left[\frac{12 E I u}{\left(h_{k} \cot \alpha+L_{1}+L_{n} / 2\right)^{3}}-\frac{q L_{k}}{2}\left(h_{k} \cot \alpha+L_{1}+\frac{L_{n}}{2}\right)+q L_{k}\left(2 h_{k} \cot \alpha+L_{1}+L_{2}+L_{n}\right)\right] .
\end{aligned}
$$


There are many parameters in formula (24). In practical application, the main conditions can be taken for calculation as per the specific conditions in compliance with burst prevention, with the aim of reducing the calculation workload.

\section{Prevention and Control of Rock Burst in Key Working Faces under Thick Magmatite in Deep Mine}

6.1. Prevention and Control Measures for Rock Burst. The main dynamic disasters in the key working faces under thick magmatite in deep mine are the flexural loading burst of thick magmatite and the shock bump burst of thick magmatite fracture. Based on the occurrence mechanism of these two dynamic disasters, the prevention and control measures for the rock burst in key working face 12310 are put forward from the perspectives of improving the overall strength of key working face blocks, weakening the effect of dynamic load from the shock bump, strengthening monitoring and support, and reducing surrounding rock stress.

6.1.1. Establish a Reasonable Width. As per formulas (22) and (23), under the condition that $P_{j}$ or $P_{D}$ is unchanged, the occurrence of those two types of dynamic disasters can be contained or reduced at the source by improving the limit compressive strength of key working face blocks. As per formula (24), in combination with the actual situation of key working face 12310, take the most dangerous condition (if the overall instability burst does not occur under the most dangerous condition for the key working face 12310) for the calculation, namely, formula (2) in (24). As per the geology and mining conditions of key working face 12310, relevant parameters are taken: $L_{k}=141 \mathrm{~m}, L_{c}=137 \mathrm{~m}, v t=64.8 \mathrm{~m}$, $L_{1}=135, L_{2}=300 \mathrm{~m}, \alpha=82^{\circ}, \beta=75^{\circ}, x_{1}=10 \mathrm{~m}, x_{2}=49 \mathrm{~m}$ (the width of pressure relief zone in middle tunnel and the width of middle tunnel), $x_{3}=15 \mathrm{~m}$ (the depth of pressure relief hole is $15 \mathrm{~m}), \varphi_{\max }=5, \varphi_{\min }=1.4, \sigma_{c}=19 \mathrm{MPa}, h_{k}=250 \mathrm{~m}$, $\gamma=25 \mathrm{kN} / \mathrm{m}^{3}, \quad h_{b}=441 \mathrm{~m}, \quad E=13 \mathrm{GPa}, \quad I=22623698 \mathrm{~m}^{4}$ (width and height of thick magmatite beam are calculated by $139 \mathrm{~m}$ (average) and $125 \mathrm{~m}$, respectively), $N=3$ times, $h_{\mathrm{c}}=3.1 \mathrm{~m}, \rho=25 \mathrm{~kg} / \mathrm{m}^{3}, T_{\mathrm{a}}=1.5 \mathrm{~s}, r=280 \mathrm{~m}, \delta=1.7, \mu=0.06$, $u=0.23 \mathrm{~m}$, and $\theta=0.2^{\circ}$. Taking the above parameters into formula (2) in formula (23), the minimum width $L_{n}$ of key working face 12310 free from overall instability burst is $286 \mathrm{~m}$, as shown in Figure 12. When the width of the key working face block is less than $286 \mathrm{~m}$, the load stress is greater than the bearing capacity, whereas the load stress is less than the bearing capacity. The design width of key working face 12310 is $301 \mathrm{~m}$, which is more than $286 \mathrm{~m}$; therefore, the overall instability burst would not occur during the mining.

6.1.2. Key Monitoring. After key working face 12310 is mined, the instability movement for the overburden under the control of thick magmatite to the earth surface occurs and the burst hazard is more serious than that of the ordinary working face; therefore, the on-site monitoring should be strengthened. The movement of thick magmatite shall be learned in real time during the mining, and the stress of surrounding rock in the working field and tunnel shall be monitored at the same time. Therefore, a joint monitoring scheme for the micro-shock bump and stress is formulated (refer to Figure 1 for the layout of measuring sites): the coal body stress measuring stations shall be set with distances of $55 \mathrm{~m}, 34 \mathrm{~m}$, and $37 \mathrm{~m}$ from the open-off cut to the belt tunnel, middle tunnel, and track tunnel, respectively. Each tunnel is arranged with 10 groups. The spacing between adjacent measuring stations within the three tunnels shall be $25 \mathrm{~m}, 25 \mathrm{~m}$, and $30 \mathrm{~m}$, respectively. Each measuring station is provided with two measuring sites, with buried depths of $8 \mathrm{~m}$ and $14 \mathrm{~m}$, respectively. The measuring stations shall be removed and set forward in time along with the mining in the working face. The measuring stations for the microshock bump in floor strata shall be set with a distance of $200 \mathrm{~m}, 300 \mathrm{~m}$, and $200 \mathrm{~m}$ from the open-off cut to the belt tunnel, middle tunnel, and track tunnel, respectively, with corresponding labels of $3 \#, 2 \#, 1 \#$, and $4 \#$. The measuring stations for the micro-shock bump in floor strata shall be, respectively, arranged near goaf 12304. 4\# measuring station for the micro-shock bump shall be fixed, and 1\#-3\# shall be removed and set forward in time along with the mining in the working face.

6.1.3. Key Speed Reduction. After the overburden movement develops to the thick magmatite due to the mining in key working face 12310, the flexural loading of thick magmatite would cause an increase in the stress in the affected area. At this time, the faster the mining in the working face, the greater the flexural loading rate of the thick magmatite, the greater the stress increase range in the affected area, and the greater the corresponding burst hazard degree. During the mining, the changes in the micro-shock bump energy and frequency during the periodic movement of the thick magmatite shall be monitored in real time. If the relevant parameters increase sharply, the speed of mining shall be reduced definitely to ensure safety.

6.1.4. Key Pressure Relief. Theoretical research and practice have proved [26-28] that pressure relief is a reliable measure to eliminate the danger of rock burst. On the one hand, pressure relief can transfer the high stress of near-field coal body to the deep part; on the other hand, it can reduce or eliminate the burst tendency of the coal body, thereby playing a protective role in tunnels or the working field. If key working face 12310 is affected by the flexural loading of the thick magmatite or the strong dynamic load of the shock bump, the hazard would be greater. For the fact that the pressure relief measures of the general working face are difficult to solve this problem, it is necessary to strengthen the pressure relief. The pressure relief of key working face 12310 shall be divided into three parts.

Comprehensive (pre) pressure relief: pre-pressure relief can destroy the coal body in advance to reduce the stress, so as not to increase the difficulty of pressure relief after being affected by flexural loading of the thick magmatite or strong 


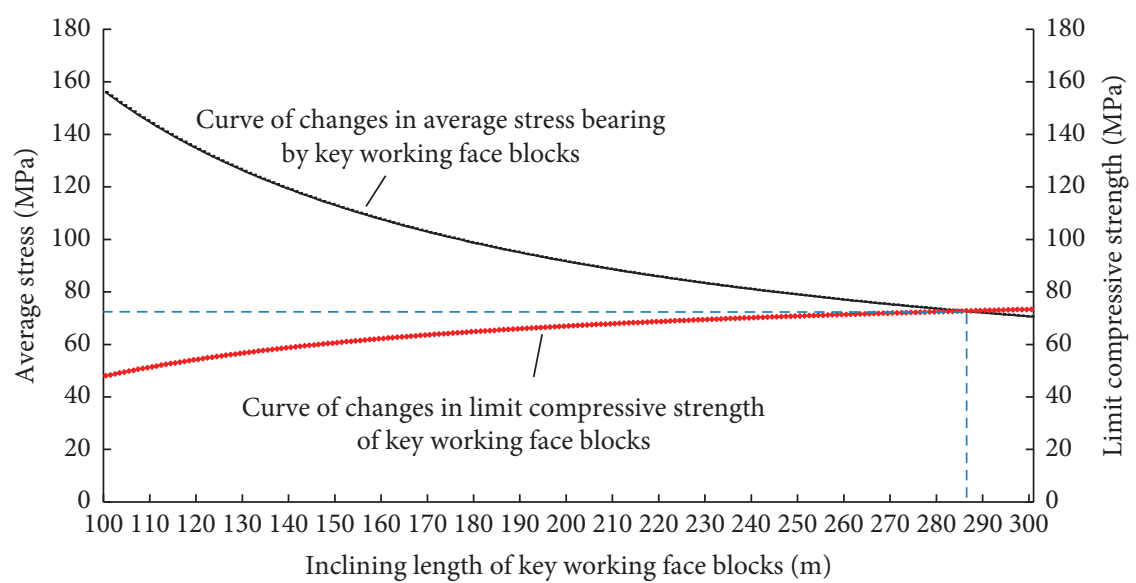

FIGURE 12: Bearing capacity of key working face blocks with different widths.

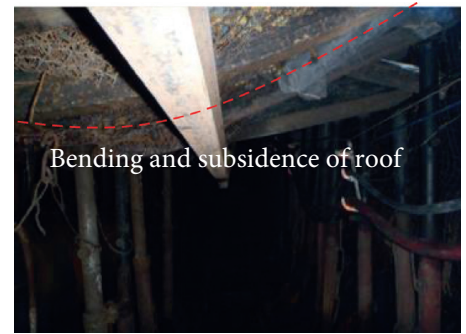

(a)

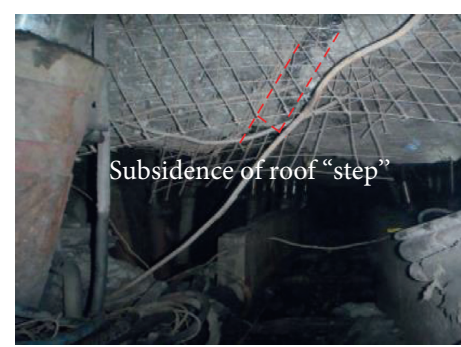

(b)

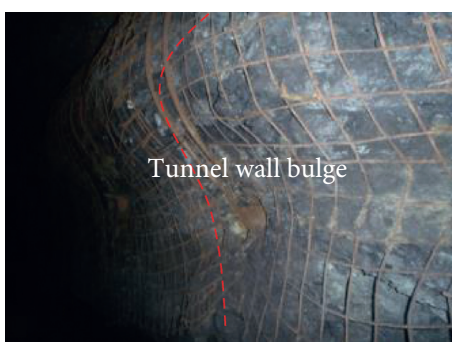

(c)

Figure 13: Deformation of advance heading in key working face. (a) Belt tunnel; (b) middle tunnel; (c) track tunnel.

dynamic load of the shock bump. The pre-pressure degree shall be moderate (large deformation or instability of tunnels is likely to occur after the pressure relief zone covers the advanced influence range of the working face) and the hole depth shall not be too large (to avoid causing excessive damage on the elastic bearing zone). The pre-pressure relief parameters are as follows: the hole depth shall be $15 \mathrm{~m}$, hole diameter $110 \mathrm{~mm}$, and hole spacing $2 \mathrm{~m}$. The pre-pressure relief measures shall be carried out before the repeated mining in the working face.

Advanced pressure relief with many times: the stress concentration degree of key working face 12310 is relatively large. After the pressure relief zone is affected in advance, the free space of the borehole would be filled and compacted quickly, the bearing capacity of the coal body would be restored, and the coal body would be transferred to the high stress migration in the far field. In addition, the strong dynamic load of the shock bump is likely to cause a sharp increase in the stress. Therefore, the coal body in the pressure relief zone shall always be maintained in a low stress state. Therefore, it is necessary to implement pressure relief measures many times on the basis of pre-pressure relief and arrange the pre-pressure relief boreholes in a spacing of $1 \mathrm{~m}$ with a distance of $350 \mathrm{~m}$ in advance.

Further pressure relief after the early warning: on account of the large range of prevention and control during the repeated mining in key working face 12310, and the uneven coal body, the implementation of comprehensive pressure relief cannot completely eliminate the disaster-causing points; therefore, it is necessary to implement accurate danger relief in time as per the monitoring results. When there are large abnormalities in quantity and total energy of the micro-shock bump, or when high-stress zone is monitored, large diameter boreholes shall be resolutely applied for further pressure relief in the early warning zone, with the aim of reducing coal body stress in time and eliminating hidden dangers of rock burst.

6.1.5. Key Support. Key support refers to a support improving the advance support strength of key working face 12310 and strengthening the surrounding rock support of tunnels. On the one hand, it is beneficial to make up for the damage of "strong pressure relief" to surrounding rock of tunnels; on the other hand, it conduces to the prevention of the rock burst or the reduction of the damage of rock burst. In order to improve the stability of the surrounding rock of tunnels, whole support in frame shall be implemented for the advance headings with an advanced distance of $120 \mathrm{~m}$ during the mining in the working face.

6.2. Project Verification. Key working face 12310 started production in January 2014 and ended in June 2015. During the mining, there were 4439 shock bumps induced by the 
fracture of thick magmatite, including 8 shock bumps with the energy of $E>10^{5} \mathrm{~J}, 566$ shock bumps with the energy of $10^{4}<E<10^{5} \mathrm{~J}, 1485$ shock bumps with the energy of $10^{3}<E<10^{4} \mathrm{~J}, 1608$ shock bumps with the energy of $10^{2}<E<10^{3} \mathrm{~J}$, and 772 shock bumps with the energy of $0<E<10^{2} \mathrm{~J}$. The shock bumps with energy $E>10^{4} \mathrm{~J}$ have a more serious burst hazard to the working face. Flexural loading of the thick magmatite caused 31 red warnings and 70 yellow warnings for the coal body stress. By setting a reasonable width and simultaneously implementing the "Four Keys" comprehensive prevention and control measures of "key monitoring + key speed reduction + key pressure relief + key support," although the roof subsidence and tunnel wall deformation of the advance heading are relatively large (Figure 13) during the mining in key working face 12310, no overall instability burst has occurred; therefore, the safe production purpose of "no disaster in bumps, no harm under burst" was realized.

\section{Conclusion}

(1) After the mining in the key working faces under thick magmatite in deep mine, the instability movement for the overburden under the control of thick magmatite to the earth surface occurs, which is the main reason for that the rock burst in the key working face under the thick magmatite in deep mine has a great hazard and wide influence.

(2) The main force sources for the burst of the key working face include the horizontal hinged "carrier" load, the vertical "loader" load, and the shock bump load from thick magmatite fracture, which are generated by the periodic fractured movement during the mining in the key working face under the thick magmatite in deep mine.

(3) The essence of burs in key working faces under thick magmatite in deep mine is the instability burst of the key working face block, which can be divided into the flexural loading burst of thick magmatite (type I) and the shock bump burst of thick magmatite fracture (type II). With the establishment of the dynamic loading model of periodic fracture of thick magmatite and the dynamic support strength model of corresponding key working face blocks, the mechanical conditions required by type I and type II bursts are deduced, respectively, and the formula for determining the design width of key working face free from overall instability burst would also be provided.

(4) The research results were applied to key working face 12310 . Therefore, the safe production purpose of "no disaster in bumps, no harm under burst" was realized by setting a reasonable width and simultaneously implementing the "Four Keys" comprehensive prevention and control measures of "key monitoring + key speed reduction + key pressure relief + key support”.

\section{Data Availability}

The data used to support the findings of this study are available from the corresponding author upon request.

\section{Conflicts of Interest}

The authors declare that they have no conflicts of interest.

\section{Acknowledgments}

The authors gratefully thank the fund of Key Scientific Research Project of Colleges and Universities in Henan Province (Grant no. 19A440012) for its financial support.

\section{References}

[1] Q. X. Qi, Y. Z. Li, S. K. Zhao, P. Z. Pan, and X. Z. Wei, "Discussion on the mechanism and control of coal bump among mine group," Journal of China Coal Society, vol. 44, no. 1, pp. 141-150, 2019.

[2] Y. Feng, F. X. Jiang, and J. D. Li, "Evaluation method of rock burst hazard induced by overall instability of island coal face," Journal of China Coal Society, vol. 40, no. 5, pp. 1001-1007, 2015.

[3] W. L. Yang, F. X. Jiang, P. Yang, Q. J. Zhu, Q. D. Wei, and C. W. Wang, "Mechanism of repeated rock bursts in extrathick coal seam," Chinese Journal of Geotechnical Engineering, vol. 37, no. 11, pp. 2045-2050, 2015.

[4] S. S. Peng, "Topical areas of research needs in ground control a state of the art review on coal mine ground control," International Journal of Mining Science and Technology, vol. 25, no. 1, pp. 1-6, 2015.

[5] J. F. Pan, Q. X. Qing, S. H. Liu, S. W. Wang, W. T. Mang, and X. C. Kang, "Characteristics, types and prevention and control technology of rock burst in deep coal mining in China," Journal of China Coal Society, vol. 45, no. 1, pp. 111-121, 2020.

[6] X. H. Li and X. D. Zhang, "Mechanism and prevention of rock-burst induced by immediate roof breakage in shallowburied coal seam," Journal of China Coal Society, vol. 42, no. 2, pp. 510-517, 2017.

[7] J. H. Lu, Y. Q. Cao, Z. Q. Wei, and W. Shen, "Research on reasonable width of partition pillar close to goaf heading mining in thick seam of deep shaft," Chinese Journal of Rock Mechanics and Engineering, vol. 34, no. 2, pp. 4269-4277, 2015.

[8] H. Lippmann, "Mechanics of "bumps" in coal mines: a discussion of violent deformations in the sides of roadways in coal seams," Applied Mechanics Reviews, vol. 40, no. 8, pp. 1033-1043, 1987.

[9] G. Bräuner, Rockbursts in Coal Mines and Their Prevention, Routledge, Milton Park, UK, 2017.

[10] J. F. Zhang, F. X. Jiang, J. B. Yang, P. Zhao, M. H. Zhai, and G. L. Wang, "Recoverability of isolated coal pillars in rockburst coal seam," Journal of Mining \& Safety Engineering, vol. 33, no. 5, pp. 867-879, 2016.

[11] M. Zhang, Y. H. Cheng, L. Wang, F. X. Jiang, and Q. Li, "Structure model and stability research of thick hard stratacoal pillar in shallow-buried re-mined panels," Chinese Journal of Rock Mechanics and Engineering, vol. 38, no. 1, pp. 87-100, 2019.

[12] P. P. Zhang, L. S. Jiang, X. F. Liu, Z. L. Zhang, and X. Liu, "Mining-induced overlying strata structure evolution characteristics and disaster-triggering under high level hard thick 
strata," Journal of Mining \& Safety Engineering, vol. 34, no. 5, pp. 852-860, 2017.

[13] H. He, L. M. Dou, S. Y. Gong, P. Zhou, and Z. J. Xue, "Rock burst rules induced by cracking of overlying key stratum," Chinese Journal of Geotechnical Engineering, vol. 32, no. 8, pp. 1260-1265, 2010.

[14] Y. D. Jiang, Y. S. Pan, F. X. Jiang, L. M. Dou, and Y. Ju, "State of the art review on mechanism and prevention of coal bumps in China," Journal of China Coal Society, vol. 39, no. 2, pp. 205-213, 2014.

[15] J. Q. Jiang, P. P. Zhang, L. Y. Pan, L. Q. Chen, and F. C. Li, "Study on microseismic distribution characteristics of highposition and ultra thick hard overlying strata under repeated mining," Coal Science and Technology, vol. 43, no. 1, pp. 21-24, 2015.

[16] P. J. Yang, Y. He, and W. B. Guo, "Disaster-causing mechanism and control measures of extremely thick and hard magmatic rock above working face," Journal of China Coal Society, vol. 38, no. 12, pp. 2106-2112, 2013.

[17] F. X. Jiang, Q. D. Wei, C. W. Wang et al., "Analysis of rock burst mechanism in extra-thick coal seam controlled by huge thick conglomerate and thrust fault," Journal of China Coal Society, vol. 39, no. 7, pp. 1191-1196, 2014.

[18] D. Y. Xuan, J. L. Xu, J. C. Feng, and W. B. Zhu, "Disaster and evolvement law of mining-induced stress under extremely thick igneous rock," Journal of China Coal Society, vol. 36, no. 8, pp. 1252-1257, 2011.

[19] J. A. Wang, H. Liu, and H. G. Ji, "Study on fracure mechanism of overlying super-thick rock stratum in underground mining," Chinese Journal of Rock Mechanics and Engineering, vol. 28, no. 1, pp. 2815-2823, 2009.

[20] X. Luo and P. Hatherly, "Application of microseismic monitoring to characterise geomechanical conditions in longwall mining," Exploration Geophysics, vol. 29, no. 3-4, pp. 489-493, 1998.

[21] F. X. Jiang, "View point of spatial structures of overlying strata and its application in coal Mine," Journal of Mining \& Safety Engineering, vol. 23, no. 1, pp. 31-33, 2006.

[22] C. W. Wang, F. X. Jiang, Q. G. Sun et al., "The forecasting method of rock-burst application based on overlying multistrata spatial structure theory," Journal of China Coal Society, vol. 34, no. 2, pp. 150-155, 2009.

[23] M. G. Qian, P. W. Shi, and J. L. Xu, Ground Pressure and Strata Control, University of Mining and Technology Press, Xuzhou, China, 2010.

[24] S. J. Gibowicz and A. Kijko, An Introduction to Mining Seismology, Earthquake Publish House, Beijing, China, 1998.

[25] X. C. Wang, F. C. Huang, H. X. Zhang, and L. G. Zhang, "Discussion and improvement for A H Wilson at coal pillar design," Journal of China Coal Society, vol. 27, no. 6, pp. 604-608, 2002.

[26] J. H. Liu, F. X. Jiang, G. J. Sun, Z. G. Zhang, and W. F. Tan, "Mechanism of intensive venting pulverized coal to prevent coal burst and its appliction," Chinese Journal of Rock Mechanics and Engineering, vol. 33, no. 4, pp. 747-754, 2014.

[27] Z. X. Yu, F. X. Jiang, B. Gui, and A. Y. Zhang, "Study and application of stress three-dimensional theory to prevention and control of mine pressure bumping," Coal Science and Technology, vol. 39, no. 7, pp. 1-4, 2011.

[28] Z. H. Guo, "Borehole destressing mechanism and key parameters determination of roadway in isolated working face," Journal of Taiyuan University of Technology, vol. 51, no. 6, pp. 906-911, 2020. 